\title{
Effective management of breathlessness: a review of potential human rights issues
}

\author{
Metin Bașoğlu \\ Affiliation: Istanbul Center for Behavior Research and Therapy (DABATEM), Istanbul, Turkey. \\ Correspondence: M. Bașoğlu, Istanbul Center for Behavior Research and Therapy (DABATEM), Sıraselviler, \\ Meșelik Sok. 26/5, Beyoğlu, Istanbul, Turkey. E-mail: mbasogludadabatem.org
}

@ERSpublications

Failure to assess and treat breathlessness properly may raise moral and human rights issues http://ow.ly/v2BN30be8a7

Cite this article as: Başoğlu M. Effective management of breathlessness: a review of potential human rights issues. Eur Respir J 2017; 49: 1602099 [https://doi.org/10.1183/13993003.02099-2016].

Chronic breathlessness is a distinct clinical syndrome defined as "breathlessness that persists despite an optimal use of the therapeutic resources available to treat the underlying causative condition" [1,2]. This is a frequent clinical condition encountered in chronic respiratory diseases, cardiac diseases, neuromuscular disorders, terminal cancers, whether respiratory or not, and in patients receiving mechanical ventilation for acute or chronic respiratory failure. The above definition includes not only chronic conditions, but also acute breathlessness that persists despite maximal pathophysiological treatment. The term "persistent" breathlessness has been proposed to encompass both acute and chronic situations [2]. Persistent or not, breathlessness is under-recognised by respiratory physicians, particularly in settings of advanced palliative care or intensive care, where verbal communication is difficult $[3,4]$, thereby leading to calls for greater awareness of this problem [5, 6]. CuRRow et al. [7] have pointed to the need to assess and treat chronic breathlessness with opioids as outlined in specialist clinical guidelines and argued that failure to do so is a breach of human rights. In this editorial, I expand further on this issue in the hope of clarifying potential moral and human rights issues in proper clinical management of chronic breathlessness or breathlessness in general. As breathlessness is an intensely traumatic event, the issue of proper psychological care of patients is also briefly addressed.

\section{The traumatic nature of breathlessness}

Breathlessness is a multidimensional symptom with a sensory and an affective component. It is commonly associated with anxiety, fear and depression in patients with chronic breathlessness [8-10]. A study [11] found that patients experiencing breathlessness under mechanical ventilation were eight times more likely to report anxiety than patients not experiencing breathlessness. Furthermore, studies [12, 13] have shown that respiratory events rank first in the list of stressful recollections in patients who develop post-traumatic stress disorder (PTSD) after an intensive care unit stay. These findings are evidence of the traumatic nature of breathlessness.

It is indeed the inherently traumatic nature of breathlessness that accounts for common use of asphyxiation as a method of torture. Its association with traumatic stress reactions is also confirmed by our studies of torture survivors. In our studies, we used a structured Exposure to Torture Scale to obtain data on the severity of distress associated with 46 different forms of torture. As this scale included measures of both objective (e.g. number of exposures) and subjective (e.g. perceived distress and uncontrollability) severity of each form of torture, we could examine the relative psychological impact of

Received: Oct 272016 | Accepted after revision: March 022017

Conflict of interest: Disclosures can be found alongside this article at erj.ersjournals.com

Copyright CERS 2017 
different torture methods. Our first study [14], conducted in the early 1990s, involved 55 survivors of torture. In this study asphyxiation was not only the most important predictor of more PTSD symptoms but also one of the few torture methods that had a cumulative psychological impact with repeated exposures. (M. Başoğlu and S. Mineka, unpublished manuscript; these findings could not be published at the time, because the study participants were concerned that they could guide torturers in designing more effective torture. They were made public in summary form many years later in 2012 in a blog article explaining why waterboarding constitutes torture [15].) A further study of 279 torture survivors in countries of the former Yugoslavia revealed similar results [16]. In a listing of 46 different forms of torture (including some excruciatingly painful physical torture methods) according to the ratings of perceived distress and uncontrollability, asphyxiation ranked first with respect to perceived uncontrollability and second (after rape) with respect to perceived distress.

The traumatic nature of asphyxiation can be explained by two factors. First, it is an extremely aversive physiological process associated with intense fear of imminent death. Second, it is a totally uncontrollable event, as our study demonstrated. There is nothing one can do to avoid it or reduce its impact and, if it continues long enough, death is inevitable. Abundant evidence from work with both animals and humans shows that unpredictable and uncontrollable stressors have greater traumatic impact than predictable and controllable stressors [17]. Helplessness induced by uncontrollable stressors leads to PTSD and hopelessness is associated with depression [18]. It could be argued that chronic breathlessness because of an underlying medical condition is worse than asphyxiation torture in terms of the duration of pain or suffering involved. The latter is a time-limited experience. Individuals know that if they survive such torture (and many do), they will be able to breathe normally again. Patients with chronic breathlessness, on the other hand, have to live with this debilitating condition for the rest of their life and are thus likely to develop more pervasive feelings of helplessness and hopelessness in the knowledge that all medical efforts have failed to alleviate their suffering. Indeed, evidence from work with patients suffering from chronic pulmonary disease [19-21] supports this point.

\section{Potential human rights issues in pharmacological treatment}

Currow et al. [7] argue that "opioids are the pharmacological therapy with the strongest evidence base" and cite evidence showing that regular low-dose sustained release oral morphine can provide relief from chronic breathlessness in cases where "disease-modifying" treatments have been exhausted and that such benefit is sustained for long periods of time in many cases. They also note that this "improved evidence has been reflected in seminal statements" by some American and Canadian professional bodies, which "remove equivocation" around this issue. On the basis of these developments, they conclude that "failure to enquire about, assess and properly treat chronic refractory breathlessness with opioids as outlined in specialist clinical guidelines is now sub-standard medical care and also a violation of the right to the highest attainable standard of physical and mental health as outlined in the International Covenant on Economic, Social and Cultural Rights. They also note that, despite these developments, "many clinicians are convinced that using opioids in patients with respiratory compromise is an unacceptable risk, despite the absence to date of any case reports in prospective studies of respiratory depression when low-dose regular opioids are used".

As a mental health professional, I am not in a position to pass judgement on these arguments. It is worth, however, pointing to some potential legal issues that might arise if certain conditions are met. For example, if one could assume that there is 1) sufficient evidence and 2) consensus on drug efficacy and safety, failure to treat persistent breathlessness with opioids could also be regarded as a violation of the United Nations Convention against Torture [22]. This Convention defines torture as "any act by which severe pain or suffering, whether physical or mental, is intentionally inflicted on a person" for certain purposes with some level of official involvement. Although this definition was originally drafted with state-perpetrated torture in mind, its interpretation is now much broader in scope, covering also ill-treatment that may amount to torture in various other institutional settings, including hospitals. Although failure to provide relief from breathlessness, when this is medically possible, does not meet the criterion of intent, it could nonetheless be legally regarded as "reckless" conduct or omission amounting to torture. Juan Méndez, the former United Nations Special Rapporteur on Torture, and Andra Nicolescu, Assistant Director, United Nations Anti-Torture initiative, note that while purely negligent conduct is not currently sufficient to qualify an act or omission as torture under international law, unintentional acts, such as deprivation of medical care or "other similarly reckless conduct or omissions in custody could amount to torture when they are known or should be known to inflict severe pain or suffering" [23].

An example relevant to breathlessness in this respect concerns denial of pain treatment. Méndez and Nicolescu [23] explain the current position of international law on this issue as follows: 
The SRT [Special Rapporteur on Torture] mandate has held that a State's failure to ensure access to controlled medicines for the relief of pain and suffering threatens fundamental rights to health and to protection against CIDT [cruel, inhuman, or degrading treatment], highlighting the fact that governments must guarantee essential medicines as part of their minimum core obligations under the right to health, and take measures to protect people under their jurisdiction from inhuman and degrading treatment... Whether the denial of pain treatment, which involves an act of omission resulting from neglect and poor government policies, will constitute CIDT or punishment will depend on whether (1) the suffering is severe and meets the minimum threshold under the prohibition against torture and ill-treatment; (2) the state is, or should be, aware of the suffering, including when no appropriate treatment is offered; and (3) the government failed to take all reasonable steps to protect individuals' physical and mental integrity. It is critical to realize that ensuring the availability and accessibility of medications included in the WHO Model List of Essential Medicines is a legal obligation under the Single Convention on Narcotic Drugs. Accordingly, when the failure of states to take positive steps, or to refrain from interfering with health-care services, condemns patients to unnecessary suffering from pain, states not only fall foul of the right to health but also violate an affirmative obligation to prevent torture and ill-treatment.

Méndez makes the same point in his 2013 report to the Human Rights Council [24]. Although chronic breathlessness is not specifically mentioned in this report, there is no reason to assume that the severity of suffering caused by breathlessness does not meet the minimum severity threshold under the prohibition against torture and ill-treatment. Evidence briefly reviewed earlier strongly suggests that breathlessness in general and chronic breathlessness in particular constitute "severe pain or suffering." Considering that asphyxiation can induce more severe pain or suffering than other forms of physical torture [16], it could be reasonably argued that, if denial of medication for chronic pain constitutes torture, then the same could also apply to breathlessness.

There is some disagreement among international law scholars, however, as to whether "reckless" acts of omission can constitute torture. GinBar [25], for example, legal adviser to Amnesty International, argues that "recklessness" does not meet the requirement of intent, while also noting that intent to torture must be individual, not institutional, although this would not rule out that certain institutional policies can be traced to the intention of specific individuals. He also notes that as assigning responsibility to individuals can be difficult in institutional contexts, a finding of "cruel, inhuman, or degrading treatment" (CIDT) might be easier to establish, as it does not require "severe pain or suffering," intent or purpose. The prohibition of CIDT is also absolute. Whichever term might be appropriate, there are clearly potential legal issues that surround withholding effective medical care. It is also worth noting in this connection that acts of "negligence" constitute CIDT in international law [23].

Having presented this legal analysis so far, it is important to emphasise once again that it pertains to a hypothetical situation. To the best of my understanding, a violation of international law or any other human rights law would occur only in situations where there is "intentional," "reckless" or "negligent" lack of adherence to well-established guidelines for "best clinical practice." If consensus on "best clinical practice" is lacking, this legal analysis should not be interpreted as incriminating clinicians who act in good faith and intentions in withholding opioid treatment because of reasonable reservations about drug efficacy or safety. But it is also worth bearing in mind that the term 'reasonable reservations' means credible research evidence to the contrary or justifiable concerns about the validity of findings reported by existing studies because of methodological problems. One might even reasonably argue, for example, that a study finding evidencing the efficacy and safety of a treatment needs to be replicated several times by methodologically sound studies before it qualifies as "best clinical practice." If reservations concerning use of opioids centre around these issues, then one might reasonably argue that more research is needed to resolve this issue. Indeed, to the best of my understanding, although the use of opioids to treat breathlessness has strong supporters, the evidence in the field does not seem to be strong enough to meet the usual standards in medicine. There seem to be questions regarding the magnitude and consistency of treatment effect, extent of improvement in activity, and the possible delimiting effects of drug tolerance on improvement.

On the other hand, accumulating sufficient evidence on these issues can be a painfully slow process, often subject to many conditions (e.g. availability of funding, bureaucracy) beyond the control of clinicians. It might help to bear this in mind in this connection that international law holds states responsible for failure to take the necessary measures to avoid unnecessary suffering in patients, as noted earlier. It could be reasonably argued that these measures include, among others, facilitating research necessary to ascertain "best clinical practice." Like severe chronic physical pain, chronic breathlessness deserves to be singled out as a medical condition that requires priority attention from all parties concerned. 
Potential legal issues aside, it is important to bear in mind that good intentions do not necessarily avoid moral issues on a different level. It might be in the interest of patients to consider several issues. First, the exceptional nature of suffering induced by persistent breathlessness, chronic or acute, comparable only to that of severe torture, places clinicians under a moral obligation to resolve their differences of opinion as urgently as possible, whether by further research or by further discussion or careful reconsideration of existing evidence with moral issues in mind. "First do no harm" is the guiding principle in medicine but there are times in medical practice when one faces 'double-bind' situations where both the use and non-use of a treatment pose potential medical problems. Such a dilemma is often resolved by a reasonable trade-off based on cost-benefit assessment. Erring on the conservative side might be the reasonable approach when there is perceived uncertainty around cost-benefit balance but sometimes this might turn out to mean greater harm than benefit for the patient, particularly when the holistic concept of health as both physical and psychological well-being is overlooked. Chronic breathlessness is one of the exceptional medical conditions where this concept needs to be even more stringently observed. More specifically, this implies that, in the absence of an alternative option, clinicians with reservations about opioids, even when their reservations are fully justifiable, may still need to reconsider their position, particularly with patients who experience high levels of breathlessness-induced distress, anxiety or fear and therefore who would be at greater risk of lasting psychological harm when deprived of rapid relief from breathlessness. This is one of the occasions where one might even be required by law to place alleviation of symptoms above safety issues. The French laws that delineate end-of-life practices, for example, clearly state that distressing symptoms must be treated effectively even if the treatment side-effects carry a risk of shortening life.

Second, it might help to bear in mind that individuals tend to underestimate the pain or distress caused by stressor events if they have not had a personal experience of similar events themselves [26] - a psychological phenomenon known as "empathy gap." Many people know what severe physical pain feels like from personal experience but very few are likely to have had an experience of breathlessness. (This psychological phenomenon explains why torture advocates find it relatively easy to convince the public that enforced asphyxiation (e.g. "waterboarding") is not severe enough to constitute torture.) It is thus important not to allow such "empathy gap" bias one's clinical judgement on this issue. It might help to ask oneself "what would I prefer as treatment if I were in this situation?" Last but not least, if risk of respiratory depression with low doses is indeed not an issue, clinicians might also consider allowing their patients to have a say in their treatment, or at least take into account their preferences, after informing them about the pros and cons of opioid treatment based on available evidence. After all, this is an important decision likely to affect the rest of their life.

\section{Issues in psychological care of patients with breathlessness}

As potential human rights issues in effective management of chronic breathlessness may go beyond the use of medications, issues in effective psychological care of patients also deserve attention. There are at least two important reasons why proper psychological care of patients with chronic breathlessness is essential. First, breathlessness is an intensely anxiety- or fear-evoking event that can lead to traumatic stress reactions, as noted earlier. Fear can lead to extensive avoidance of trauma reminders or situations/ activities perceived as posing further threat to safety, which can cause significant functional impairment in important life areas and also contribute to depression [18]. This is also a common problem in patients with chronic breathlessness [27], which requires attention. Second, anxiety is likely to cause hyperventilation, which would in turn further aggravate breathlessness [28] and increase the burden of breathing in a manner independent from the metabolic needs of the body [29]. Thus, effective treatment of traumatic stress might well turn out to be an essential component of "best clinical practice" in management of breathlessness itself.

In view of these considerations, choice of the right intervention is critically important in treating traumatic stress. Among current treatments, "exposure-based interventions," such as cognitive-behavioural treatment (CBT), behavioural (exposure) treatment and prolonged exposure have the strongest evidence base and thus widely considered to be the treatment of choice in anxiety disorders and PTSD. CBT appears to be most commonly used in patients with chronic breathlessness. The choice of CBT as an evidence-based treatment may perhaps not raise the same issues as opioid treatment but it is worth noting here that exposure-based treatments have certain problems that might limit their usefulness in treating chronic breathlessness. Most importantly, because they all aim for anxiety reduction, treatment not uncommonly fails when anxiety cannot be reduced for various reasons [18]. This problem is often encountered in ongoing traumatic situations where anxiety occurs, not solely because of "catastrophising" thoughts, but also as a natural response to continuing realistic threats to safety or well-being. In torture survivors who face a realistic threat of re-arrest and torture, for example, one cannot reasonably expect sufficient anxiety reduction with CBT focusing solely on restructuring of "catastrophic thoughts". This also applies to chronic breathlessness, considering that, although some patients may overestimate risks to their safety (e.g. 
with physical exercise) to some extent, the intense discomfort or physiological distress caused by breathlessness is very real and naturally anxiety-evoking. This problem can be circumvented only by an intervention that aims for anxiety tolerance or resilience against anxiety, rather than anxiety reduction.

Furthermore, what works with exposure-based treatments and their mechanisms of action are largely uncertain. For example, CBT protocols often involve a combination of interventions, such as imaginal exposure, live exposure (i.e. exposure to trauma cues in natural environment), cognitive restructuring, anxiety management, skills training and problem-solving techniques. Owing to the scarcity of dismantling studies, the relative contributions of these interventions to overall improvement are largely unknown. A meta-analytic study [30] of 41 randomised controlled trials of CBT in PTSD found that cognitive restructuring alone or CBT not involving any form of exposure is less effective than $\mathrm{CBT}$ involving live exposure. Our treatment studies [31-33] clearly demonstrate that live exposure alone (focusing on enhancement of sense of control over or resilience against anxiety, rather than anxiety reduction) with no systematic cognitive interventions can achieve substantial improvement in both PTSD and depression, even when delivered in a single session [18]. Furthermore, reduction in behavioural avoidance early in treatment is the single most important predictor of overall improvement [34]. That reduction in behavioural avoidance plays a more important role in general improvement than reduction in anxiety (or panic) has also been demonstrated in panic disorder with agoraphobia [35]. All these findings imply that reduction of avoidance through live exposure is the critical therapeutic ingredient in CBT programmes. It is thus important for "best clinical practice" purposes to ensure that this important therapeutic element is not overlooked in choice of treatment protocols to avoid problems of partial improvement and substantial residual symptomatology. Persistent avoidance of activities involving physical exercise in patients with chronic breathlessness might be particularly problematic, as it is likely to reduce quality of life. A critical review of CBT studies in this field cannot be attempted here but a careful examination of their findings in light of this discussion is likely to reveal these problems.

\section{Conclusions}

To conclude, there are potential human rights issues in proper assessment and treatment of persistent breathlessness, whether acute or chronic, which appear to hinge on consensus on well-established guidelines for "best clinical practice." It is worth bearing in mind that "best medical practice" means an obligation for practitioners to try their best rather than an obligation to succeed. An awareness of the sensitive nature of the issue and a proactive, systematic and empathic approach in identifying and addressing breathlessness in all contexts, as well as at individual (best practice) and collective (research organisation and funding) levels can avoid protracted debate and potential human rights issues. Furthermore, even if the differences in opinion regarding use of opioids can be resolved in favour of the medication, "best clinical practice" needs to include not just opioids but also effective prevention and psychological treatment of traumatic stress in patients. Considering the interaction between anxiety and breathlessness, proper psychological care, with well-informed choice of interventions, might perhaps even be a useful alternative to opioid treatment or at least eliminate the need for long-term use of the medication in some cases. Further research to explore such prospects seems well worthwhile.

\section{Acknowledgements}

Thanks are due to Thomas Similowski for his valuable comments on the manuscript. This article was prepared as part the author's research and knowledge dissemination programme supported by Spunk Fund, Int.

\section{References}

1 Johnson MJ, Currow DC. Chronic refractory breathlessness is a distinct clinical syndrome. Curr Opin Support Palliat Care 2015; 9: 203-205.

2 Johnson M, Yorke J, Hansen-Flaschen J, et al. Towards an expert consensus to delineate a clinical syndrome of chronic breathlessness. Eur Respir J 2017; 49: 1602277.

3 Gysels M, Higginson IJ. Access to services for patients with chronic obstructive pulmonary disease: the invisibility of breathlessness. J Pain Symptom Manage 2008; 36: 451-460.

4 Haugdahl HS, Storli SL, Meland B, et al. Underestimation of patient breathlessness by nurses and physicians during a spontaneous breathing trial. Am J Respir Crit Care Med 2015; 192: 1440-1448.

5 Chanques G, Nelson J, Puntillo K. Five patient symptoms that you should evaluate every day. Intensive Care Med 2015; 41: 1347-1350.

6 Schmidt M, Banzett RB, Raux M, et al. Unrecognized suffering in the ICU: addressing dyspnea in mechanically ventilated patients. Intensive Care Med 2014; 40: 1-10.

7 Currow DC, Abernethy A, Ko DN. The active identification and management of chronic refractory breathlessness is a human right. Thorax 2014; 69: 393-394.

8 Parshall MB, Schwartzstein RM, Adams L, et al. An official American Thoracic Society statement: update on the mechanisms, assessment, and management of dyspnea. Am J Respir Crit Care Med 2012; 185: 435-452.

9 Banzett RB, O'Donnell CR, Guilfoyle TE, et al. Multidimensional dyspnea profile: an instrument for clinical and laboratory research. Eur Respir J 2015; 45: 1681-1691. 
10 Booth S, Lansing R. The construct of breathlessness. In: Bausewein C, Currow DC, Johnson MJ, eds. Palliative Care in Respiratory Disease (ERS Monograph). Sheffield, European Respiratory Society, 2016; pp. 85-101.

11 Schmidt M, Demoule A, Polito A, et al. Dyspnea in mechanically ventilated critically ill patients. Crit Care Med 2011; 39: 2059-2065.

12 Miranda SD, Pochard F, Chaize M, et al. Postintensive care unit psychological burden in patients with chronic obstructive pulmonary disease and informal caregivers: a multicenter study. Crit Care Med 2011; 39: 112-118.

13 Rotondi AJ, Chelluri L, Sirio C, et al. Patients' recollections of stressful experiences while receiving prolonged mechanical ventilation in an intensive care unit. Crit Care Med 2002; 30: 746-752.

14 Başoğlu M, Paker M, Paker O, et al. Psychological effects of torture: a comparison of tortured with nontortured political activists in Turkey. Am J Psychiatry 1994; 151: 76-81.

15 Başoğlu M. Waterboarding is severe torture: Research findings. Mass Trauma, Mental Health \& Human Rights. https://metinbasoglu.wordpress.com/2012/12/25/waterboarding-is-severe-torture-research-findings/ Date last updated: December 25, 2012. Date last accessed: August 27, 2016.

16 Başoğlu M, Livanou M, Crnobarić C. Torture vs other cruel, inhuman, and degrading treatment: Is the distinction real or apparent? Arch Gen Psychiatry 2007; 64: 277-285.

17 Başoğlu M, Mineka S. The role of uncontrollable and unpredictable stress in post-traumatic stress responses in torture survivors. In: Başoğlu M, ed. Torture and its Consequences: Current Treatment Approaches. Cambridge, Cambridge University Press, 1992; pp. 182-225.

18 Başoğlu M, Şalcıoğlu E. A Mental Healthcare Model for Mass Trauma Survivors: Control-Focused Behavioral Treatment of Earthquake, War, and Torture Trauma. Cambridge, Cambridge University Press, 2011; pp. 39-64.

19 Gysels M, Higginson IJ. The experience of breathlessness: the social course of chronic obstructive pulmonary disease. J Pain Symptom Manage 2010; 39: 555-563.

20 Disler RT, Green A, Luckett T, et al. Experience of advanced chronic obstructive pulmonary disease: metasynthesis of qualitative research. J Pain Symptom Manage 2014; 48: 1183-1199.

21 Solomon BK, Wilson KG, Henderson PR, et al. Loss of dignity in severe chronic obstructive pulmonary disease. J Pain Symptom Manage 2016; 51: 529-537.

22 UN General Assembly. Convention Against Torture and Other Cruel, Inhuman or Degrading Treatment or Punishment. www.ohchr.org/EN/ProfessionalInterest/Pages/CAT.aspx Date last updated: December 10, 1984. Date last accessed: August 27, 2016.

23 Méndez J, Nicolescu A. Evolving standards for torture in international Law. In: Başoğlu M, ed. Torture and Its Definition in International Law. New York, Oxford University Press (in press).

24 UN Human Rights Council. Report of the special rapporteur on torture and other cruel, inhuman or degrading treatment or punishment, A/HRC/22/53. www.ohchr.org/Documents/HRBodies/HRCouncil/RegularSession/ Session22/A.HRC.22.53_English.pdf Date last updated: February 1, 2013. Date last accessed: August 27, 2016.

25 Ginbar Y. Making human rights sense of the torture definition. In: Başoğlu M, ed. Torture and Its Definition in International Law. New York, Oxford University Press (in press).

26 Nordgren LF, McDonnell MH, Loewenstein G. What constitutes torture? Psychological impediments to an objective evaluation of enhanced interrogation tactics. Psychol Sci 2011; 22: 689-694.

27 Lansing RW, Gracely RH, Banzett RB. The multiple dimensions of dyspnea: review and hypotheses. Respir Physiol Neurobiol 2009; 167: 53-60.

28 Ley R. The modification of breathing behavior. Pavlovian and operant control in emotion and cognition. Behav Modif 1999; 23: 441-479.

29 Van Diest I, Janssens T, Bogaerts K, et al. Affective modulation of inspiratory motor drive. Psychophysiology 2009; 46: 12-16.

30 Şalcıoğlu E, Başoğlu M. What works best in cognitive behavioral treatment? A meta-analysis of therapeutic ingredients of treatment protocols for PTSD. Eur J Psychotraumatol 2011; 2 Suppl 1: S113-S114.

31 Başoğlu M, Livanou M, Şalcığlu E, et al. A brief behavioural treatment of chronic post-traumatic stress disorder in earthquake survivors: Results from an open clinical trial. Psychol Med 2003; 33: 647-654.

32 Başoğlu M, Şalcıoğlu E, Livanou M, et al. Single-session behavioral treatment of earthquake-related posttraumatic stress disorder: a randomized waiting list controlled trial. J Traumatic Stress 2005; 18: 1-11.

33 Başoğlu M, Salcıoğlu E, Livanou M. A randomized controlled study of single-session behavioral treatment of earthquake-related posttraumatic stress disorder using an earthquake simulator. Psychol Med 2007; 37: 203-214.

34 Salcioğlu E, Başoğlu M, Livanou M. Effects of live exposure on symptoms of posttraumatic stress disorder: The role of reduced behavioural avoidance in improvement. Behav Res Ther 2007; 45: 2268-2279.

35 Başoğlu M, Marks IM, Kılıç C, et al. The relationship between panic, anticipatory anxiety, agoraphobia, and global improvement in panic disorder with agoraphobia treated with alprazolam and exposure. Br J Psychiatry 1994; 164: $647-652$. 